\title{
Mark Juergensmeyer, Terror in the mind of God. The global rise of religious violence
}

Los Angeles-Londres-Berkeley, University of California Press, 2000, 316 p. (bibliogr., index). Et, en version française, Au nom de Dieu, ils tuent ! Chrétiens, juifs, musulmans, ils revendiquent la violence, Paris, Autrement, 2003, 237 p. (coll. « Frontières »)

Nathalie Luca

\section{OpenEdition}

Journals

Édition électronique

URL : http://journals.openedition.org/assr/2590

DOI : $10.4000 /$ assr.2590

ISSN : $1777-5825$

Éditeur

Éditions de l'EHESS

Édition imprimée

Date de publication : 1 octobre 2004

Pagination : $53-158$

ISBN : 2-222-96754-6

ISSN : 0335-5985

\section{Référence électronique}

Nathalie Luca, « Mark Juergensmeyer, Terror in the mind of God. The global rise of religious violence », Archives de sciences sociales des religions [En ligne], 128 | octobre - décembre 2004, document 128.68, mis en ligne le 18 novembre 2005, consulté le 24 septembre 2020. URL : http:// journals.openedition.org/assr/2590 ; DOI : https://doi.org/10.4000/assr.2590 
parentalité et le mariage, d'autre part et enfin par la perspective résolument multidisciplinaire. Cependant, de nombreuses interrogations dans des textes parfois très courts ouvrent sur des horizons vertigineux sans apporter ni réponses ni pistes pour poursuivre la réflexion, laissant le lecteur perplexe.

Martine Gross.

Terror in the Mind of God. The Global Rise of Religious Violence. Los Angeles-LondresBerkeley, University of California Press, 2000, 316 p. (bibliogr., index). Et, en version française, Au nom de Dieu, ils tuent! Chrétiens, juifs, musulmans, ils revendiquent la violence, Paris, Autrement, 2003, 237 p. (coll. «Frontières »).

En s'attachant aux dénouements d'actes religieux terroristes, l'auteur cherche les différents paramètres rendant possible l'exercice de la violence. Au cœur de celle-ci réside bien sûr une interprétation rigide du bien et du mal qui pose le monde en état de guerre. M.J. s'intéresse aux portraits sociologiques de ceux qui s'engagent dans ces guerres sans fin prévisible. Une bonne introduction sur les dérives religieuses.

Nathalie Luca.

KETOLA (Kimmo).

An Indian Guru and his Western Disciples. Representation and Communication of Charisma in the Hare Krishna Movement. Helsinki, Yliopistopaino, 2002. 221 p. (bibliogr., index, glossaire).

Cet ouvrage propose une étude du charisme en s'appuyant sur une approche cognitive, et en prenant pour objet les interactions entre le guru et ses disciples au sein du mouvement Hare Krishna (on regrettera quelque peu ce choix de cas d'études: le guru est certes une figure complexe et passionnante d'autorité religieuse, mais pourquoi choisir un mouvement au sein duquel le leader est décédé depuis plusieurs années ? Ceci oblige l'auteur, souhaitant pourtant s'inscrire dans une démarche ethnographique, à s'appuyer principalement sur des sources écrites). Ce travail se décline en trois volets : après un état des lieux des perspectives théoriques abordant le charisme, K.K. analyse la transmission des représentations du charisme du guru, Swami Prabhupada via les doctrines et les pratiques d'Hare Krishna, ainsi que les interactions entre le guru et ses disciples. Dans un troisième temps, il donne une interprétation plus théorique des données précédemment présentées.

Dans son état des lieux de l'étude du charisme, l'A. note que la sociologie et l'anthropologie tendent à se focaliser sur les contextes sociaux dans lesquels apparaissent des leaders charismatiques porteurs d'un message de délivrance, sur la pertinence de leur message pour leurs disciples, et sur la routinisation du charisme. Dans le champ de la psychologie, on insiste plutôt sur la personnalité et les traits psychologiques susceptibles de rendre certains individus sensibles au charisme. Prenant une distance critique avec les sciences sociales insistant sur les déterminants socioculturels de la reconnaissance du charisme, K.K. prend pour référence les sciences cognitives et s'appuie plus particulièrement sur les travaux de $\mathrm{D}$. Sperber, P. Boyer, G. Bateson et sur Les cadres de l'expérience d'Erving Goffman.

La seconde partie de l'ouvrage présente tout d'abord la relation entre guru et disciples telle qu'elle est définie dans les doctrines d'Hare Krishna, et telle qu'elle s'exprime dans l'exercice de l'autorité au sein du mouvement. Les rituels et les activités quotidiennes décrits par l'A. permettaient le contact avec le guru lorsqu'il était en vie. Ils produisent également des émotions et transmettent les conceptions religieuses du mouvement, entre autres en ce qui concerne la nature du guru. En s'appuyant sur les témoignages de disciples, K.K. avance que le comportement du guru suscite une « rupture de cadre » selon l'approche goffmanienne: le charisme de Prabhupada ne tient pas à ce qu'il incarne les idéaux et les valeurs de son audience, mais à ce que son comportement exotique au sens profond du terme, contradictoire, surprenant, défie et perturbe les attentes de son public. Il en est de même pour les qualités que l'on reconnaît au guru : un esprit impénétrable, une capacité de lire dans l'esprit de ses fidèles, une influence sur les évènements, des manifestations par une lumière ou des vibrations, signes directs de son essence particulière... Ces représentations autour du charisme du guru conduisent les disciples à réinterpréter les défaillances de celui-ci (ses erreurs de jugement, ses prédictions non réalisées, son décès) comme l'inaccessibilité, pour le commun des mortels, d'une réalité transcendant les apparences.

La troisième partie propose une interprétation théorique des résultats. L'A. réfute les analyses sociologiques postulant que les mouvements religieux tels Hare Krishna répondaient aux attentes de la jeunesse protestataire des années soixante. Le cadre rituel religieux hindou ne permet pas non plus, selon lui, d'expliquer la 